\title{
ANALISIS SENSITIVITAS USAHA 'SOMA PAJEKO' DARI NELAYAN YANG MENDARATKAN IKANNYA DI PELABUHAN PERIKANAN PANTAI TUMUMPA DI KELURAHAN TUMUMPA II, KECAMATAN TUMINTING, KOTA MANADO
}

\author{
Gruimaldy Kalahatu'; Victoria E.N. Manoppo²; Steelma V. Rantung² \\ 1)Mahasiswa Fakultas Perikanan dan IImu Kelautan Universitas Sam Ratulangi Manado \\ 2) Staff Pengajar Fakultas Perikanan dan IImu Kelautan Universitas Sam Ratulangi Manado \\ Koresponden email : aldygodwin@gmail.com
}

\begin{abstract}
The objectives of this study are: 1. To analyze the feasibility and sensitivity of the business of 'Soma Pajeko' from fishermen who landed their fish at Tumumpa Beach Fisheries Port, Tumumpa II Village, Tuminting District, Manado City. 2. To identify and analyze the business constraints of 'Soma Pajeko' from Fishermen who landed their fish at Tumumpa Beach Fisheries Port, Tumumpa II Village, Tuminting District, Manado City. The method in this study is the survey method. Data to be collected comes from primary data and secondary data. Primary data is data that will be obtained from interviews filling out questionnaires, observations, photos and videos, then secondary data comes from Tumumpa Beach Fisheries Port office in Tumumpa II and DKP Subdistrict, North Sulawesi Province and Library Study, in the form of previous studies that are well related which has been and has not been journalized. The research will be analyzed in descriptive qualitative and quantitative descriptive analysis. To answer the research objectives, sensitivity analysis will be used using NPV, B / C Ratio and IRR calculations.
\end{abstract}

Key Words: Sensitivity, Soma Pajeko, Fisherman, Tumumpa II Village

\begin{abstract}
Abstrak
Tujuan dari dari penelitian ini adalah: 1. Untuk menganalisis kelayakan dan sensitivitas usaha 'soma pajeko' dari Nelayan yang mendaratkan ikannya di Pelabuhan Perikanan Pantai (PPP) Tumumpa, Kelurahan Tumumpa II, Kecamatan Tuminting, Kota Manado. 2. Untuk mengidentifikasi dan menganalisis kendala-kendala usaha 'soma pajeko' dari Nelayan yang mendaratkan ikannya di Pelabuhan Perikanan Pantai (PPP) Tumumpa, Kelurahan Tumumpa II, Kecamatan Tuminting, Kota Manado. Metode dalam penelitian ini adalah metode survei. Data yang akan dikumpulkan berasal dari data primer dan data sekunder. Data primer yaitu data yang akan diperoleh dari wawancara pengisian kuisioner, observasi, foto dan video selanjutnya data sekunder berasal dari kantor Pelabuhan Perikanan Pantai (PPP) Tumumpa di Kelurahan Tumumpa II dan DKP Provinsi Sulut dan Studi Pustaka yaitu berupa penelitian-penelitian sebelumnya yang berkaitan baik yang sudah dan belum dijurnalkan. Penelitian akan dianalisis secara analisis deskriptif kualitatif dan deskriptif kuantitatif. Untuk menjawab tujuan penelitian maka akan digunakan analisis sensitivitas dengan menggunakan perhitungan NPV, B/C Ratio dan IRR.
\end{abstract}

Kata Kunci: Sensitivitas, Soma Pajeko, Nelayan, Kelurahan Tumumpa II

\section{PENDAHULUAN}

Pembangunan perikanan yang telah dilaksanakan di Indonesia selama ini belum bisa dikatakan telah berjalan dengan baik. Hal ini terlihat dari belum optimalnya kontribusi perikanan bagi ekonomi finansial dan kesejahteraan nelayan yang umumnya tergolong rendah. Kontribusi perikanan belum terlihat secara signifikan dibandingkan dengan sektor perdagangan, pertambangan dan pertanian.

Selanjutnya, Wiyono (2012) dalam jurnal Buletin PSP menulis bahwa banyak pengelolaan usaha perikanan yang belum baik terutama dari aspek kelayakan finansial dan pengelolaan faktor produksi yang dibutuhkan dalam operasi penangkapan.
Salah satu provinsi yang memiliki potensi perikanan yang cukup besar adalah Sulawesi Utara yaitu luas wilayahnya sekitar $\pm 110.000 \mathrm{~km}^{2}$ dengan panjang garis pantai $\pm 1.740 \mathrm{~km}$ dan memiliki potensi ikan 500.000 ton per tahun. Provinsi ini telah menjadikan hasil usaha perikanan dan kelautan sebagia salah satu produk unggulan untuk memacu peningkatan pendapatan asli daerah. Pembangunan sub sektor perikanan dan Kelautan di Sulawesi Utara hingga saat ini telah memperlihatkan kemajuan yang relatif berarti. Tahun 2017, produksi perikanan tercatat $818.192,3$ ton atau meningkat 5,99\% dibanding tahun sebelumnya sebesar $771.88,28$ ton. Konsumsi sebesar $58,88 \mathrm{~kg} / \mathrm{kapita/tahun}$ 
meningkat $0,41 \%$ dan ekpor komoditi perikanan mengalami kenaikan dari $20.734 .344,37 \mathrm{~kg}$ menjadi $22.161 .387,81 \mathrm{~kg}$ di tahun 2017. Usaha perikanan tangkap menjadi tumpuan dari sebagian besar komunitas nelayan yang menempati wilayah pesisir Sulawesi Utara. Usaha perikanan tangkap ini dikembangkan dari usaha yang sifatnya tradisional menjadi usaha yang lebih profesional, sehingga meningkatkan pendapatan dan kesejahteraan hidup nelayan serta memberikan kontribusi yang signifikan dalam mengisi kas daerah (Kenanga, 2012).

Provinsi Sulawesi Utara merupakan wilayah yang cocok untuk dikembangkannya kegiatan penangkapan ikan dengan menggunakan pukat cincin (purse seine), karena lokasinya masih terjangkau juga tersedianya kemudahan penyediaan sarana dan prasarana pendukung kegiatan penangkapan ikan seperti Pangkalan Pendaratan Ikan (PPI) maupun Tempat Pelelangan Ikan (TPI) karena itu pemasaran produk perikanan tangkap yang bersifat lokal dan nasional dipastikan tidak mengalami kesulitan. Operasi penangkapan ikan dengan alat tangkap purse seine merupakan salah satu metode pemanfaatan ikan-ikan pelagis yang ada di suatu perairan. Alat tangkap purse seine banyak digunakan oleh nelayan di Sulawesi Utara. Skala produksi purse seine mulai dari skala kecil, menengah dan besar, maka purse seine menyerap tenaga kerja yang relatif tinggi. Selain itu produktivitas purse seine yang tinggi, sangat berperan besar dalam industri perikanan di Indonesia. Purse seine adalah suatu alat penangkapan ikan yang digolongkan dalam kelompok jaring lingkar. Faktor melingkarkan jaring dan penarikan tali kolor (purse line) merupakan faktor keberhasilan dalam penangkapan dengan menggunakan purse seine (Hermawan, 2016).
Selain sarana-sarana yang dibutuhkan di atas, juga ada Pelabuhan Perikanan Pantai (PPP) seperti yang terdapat di Tumumpa II, Kecamatan Tuminting, Kota Manado. Hasil prasurvei menunjukkan bahwa purse seine yang ada di Pelabuhan Perikanan Pantai (PPP) yaitu berjumlah 160 unit yang sedang aktif beroperasi, namun apakah dari jumlah tersebut layak dilanjutkan atau tidak, atau memerlukan pembenahan lanjutan demi memperoleh hasil yang benar, bisa memberi pemasukan pendapatan yang bernilai positif bagi nelayan 'soma pajeko' Selain itu pula seringkali para nelayan dihadapkan dengan berbagai perubahan faktor-faktor produksi yang berdampak pada proses produksi. Seberapa jauh perubahan faktor-faktor produksi berdampak pada proses produksi? Untuk menjawab pertanyaan tersebut penulis tertarik untuk mengadakan penelitian tentang keadaan nelayan 'soma pajeko' yang mendaratkan ikan di Pelabuhan Perikanan Pantai (PPP) Tumumpa di Kelurahan Tumumpa II, Kecamatan Tuminting, Kota Manado.

\section{METODE PENELITIAN}

Metode yang digunakan dalam penelitian ini adalah metode survei. Survei ini dilakukan di Pelabuhan Perikanan Pantai (PPP) Kelurahan Tumumpa terhadap nelayan 'soma pajeko' yang telah menjadi responden selama lima bulan.

Data yang dikumpulkan berasal dari data primer dan data sekunder. Data primer yaitu data yang diperoleh dari wawancara pengisian kuisioner, observasi/pengamatan langsung, foto dan video dari sejumlah responden di lokasi penelitian. Data sekunder berasal dari kantor Pelabuhan Perikanan Pantai (PPP) Tumumpa di Kelurahan Tumumpa II dan Kantor Dinas Kelautan Perikanan Provinsi Sulut serta studi pustaka di Perpustakaan Agrobisnis 
dan FPIK Unsrat yaitu berupa penelitianpenelitian sebelumnya.

Populasi dalam penelitian ini adalah nelayan 'soma pajeko' yang mendaratkan ikan di Pelabuhan Perikanan Pantai (PPP) Tumumpa, Kelurahan Tumumpa II, Kecamatan Tuminting, Kota Manado'. Nelayan pemilik 'soma pajeko' yang berjumlah 55 orang. Tahapan pengambilan sampel.

Guna menjawab tujuan penelitian ini dilakukan secara analisis deskriptif kualitatif dan deskriptif kuantitatif dengan menggunakan rumus sebagai berikut:

\section{Total Profit}

1. Penerimaan total dikurangi biaya total (total profit $=\mathrm{TR}-\mathrm{TC}$ )

2. Hasil kali jumlah output yang dijual dengan selisih antara penerimaan ratarata dengan biaya rata-rata (total profit $=$ $x Q$ ).

3. Penjumlahan dari selisih antara penerimaan marginal dengan biaya marginal $($ Total Profit $=\Sigma($ MR-MC).

\section{Net Benefit Cost Ratio (Net B/C Ratio)}

Rumus yang digunakan untuk menghitung Net $\mathrm{B} / \mathrm{C}$ adalah:

$$
\left[N E T B / C=\frac{\sum_{t=1}^{n} \frac{B_{t}-C_{t}}{(1+i)^{t}}}{\sum_{t=1}^{n} \frac{C_{t}-B_{t}}{(1+i)^{t}}}\right.
$$

$\mathrm{B}_{\mathrm{t}}=$ Manfaat (Benefit) pada tahun ke-t

$\mathrm{C}_{t} \quad=$ Biaya (Cost) pada tahun ke-t

$\mathrm{i}=$ Discount Factor

$\mathrm{t} \quad=$ Umur proyek

\section{Net Present Value (NPV)}

Rumus umum yang digunakan dalam perhitungan NPV adalah:

$$
N P V=\sum_{t=1}^{T} \frac{C_{t}}{(1+r)^{t}}-C_{0}
$$

NPV = Net Present Value (dalam Rupiah)

$\mathrm{Ct} \quad=$ Arus Kas per Tahun pada Periode $\mathrm{t}$
$\mathrm{CO}=\quad$ Nilai Investasi awal pada tahun ke 0 (dalam Rupiah)

$r=$ Suku Bunga atau discount Rate (dalam \%)

Jika NPV > 0, maka usaha yang dijalankan layak untuk dilaksanakan.

Jika NPV < 0, maka usaha yang dijalankan tidak layak untuk dilaksanakan.

Jika NPV $=0$, maka usaha yang dijalankan tidak rugi dan tidak untung

Internal Rate of Return (IRR)

$$
I R R=i_{1}+\frac{N P V_{1}}{\left(N P V_{1}-N P V_{2}\right)}\left(i_{2}-i_{1}\right) \ldots
$$

Keterangan:

IRR = Internal Rate of Return

i1 = Tingkat Diskonto yang menghasilkan NPV+

i2 = Tingkat Diskonto yang menghasilkan NPV-

NPV1 = Net Present Value bernilai positif

NPV2 = Net Present Value bernilai negatif

\section{Variabel-variabel Data Untuk Analisis}

Variabel-variabel yang telah diambil data untuk dianalisis: ukuran kapal dan alat tangkap soma, lama trip, kebutuhan bahan bakar, kebutuhan es, kebutuhan air tawar, ABK, kebutuhan perbekalan, biaya perawatan, musim penangkapan, jumlah produksi harga jual, system bagi hasil dan lainnya yang menggambarkan potensi kebutuhan produksi dan kelayakan usaha soma pajeko.

Variabel-variabel yang diukur dalam penelitian ini adalah:

1. Biaya tetap selama 1 tahun dihitung dalam rupiah,

2. Biaya tidak tetap selama 1 tahun dihitung dalam rupiah,

3. Keuntungan, yaitu penerimaan total dikurangi biaya total selama 1 tahun dihitung dalam rupiah,

4. Penerimaan total dari produksi selama 1 tahun dihitung dalam rupiah,

5. Harga jual. 


\section{HASIL DAN PEMBAHASAN}

\section{Soma Pajeko}

Berbagai macam alat tangkap untuk menangkap ikan di laut, salah satu adalah soma pajeko atau purse seine dimana alat ini banyak diusahakan di laut sekitar Desa Tumumpa. Nelayan yang ada di lokasi tersebut memilih usaha soma pajeko karena peluang dan usaha soma pajeko sangat menjanjikan dan mendukung program pemerintah saat ini yang berfokus di bidang perikanan dan kelautan.

Pada hakekatnya usaha soma pajeko membutuhkan manajemen yang mengatur dan menggerakkan orang-orang serta sumberdaya lainnya untuk mencapai tujuan yang diharapkan. Untuk itu diperlukaan suatu analisis yang bisa dikatakan usaha itu layak atau tidak.

\section{Analisis Finansial}

Bisnis atau suatu usaha sangat rentan terhadap perubahan akibat beberapa hal:

1. Harga,

2. Keterlambatan pelaksanaan,

3. Kenaikan biaya,

4. Ketidaktepatan dari perolehan hasil (produksi)

\section{Biaya Investasi}

Tabel 1. Biaya Investasi Nelayan Soma Pajeko di Pelabuhan Perikanan Pantai Tumumpa Kelurahan Tumumpa Dua

\begin{tabular}{|l|r|r|r|r|}
\hline \multicolumn{1}{|c|}{ Investasi } & Soma & \multicolumn{1}{c|}{ Kapal } & \multicolumn{1}{c|}{ Mesin } & \multicolumn{1}{c|}{ Jumlah } \\
\hline KM Rico & 150.000 .000 & 1.900 .000 .000 & 50.000 .000 & 2.100 .000 .000 \\
\hline KM Laut Teberau & 200.000 .000 & 3.410 .000 .000 & 400.000 .000 & 4.010 .000 .000 \\
\hline KM Makarios & 200.000 .000 & 1.940 .000 .000 & 600.000 .000 & 2.740 .000 .000 \\
\hline KM Eunzo & 250.000 .000 & 1.950 .000 .000 & 3.000 .000 .000 & 5.200 .000 .000 \\
\hline KM Getsemani & 200.000 .000 & 2.450 .000 .000 & 400.000 .000 & 3.050 .000 .000 \\
\hline KM Genesaret & 260.000 .000 & 3.960 .000 .000 & 500.000 .000 & 4.720 .000 .000 \\
\hline Jumlah & 1.260 .000 .000 & $\mathbf{1 5 . 6 1 0 . 0 0 0 . 0 0 0}$ & $\mathbf{4 . 9 5 0 . 0 0 0 . 0 0 0}$ & $\mathbf{2 1 . 8 2 0 . 0 0 0 . 0 0 0}$ \\
\hline Rata-rata & $\mathbf{2 1 0 . 0 0 0 . 0 0 0}$ & $\mathbf{2 . 6 0 1 . 6 6 6 . 6 6 7}$ & $\mathbf{8 2 5 . 0 0 0 . 0 0 0}$ & $\mathbf{3 . 6 3 6 . 6 6 6 . 6 6 7}$ \\
\hline
\end{tabular}

Sumber: Hasil Dan Olahan Data, 2019

Dari hasil wawancara diperoleh biaya investasi yang dipergunakan untuk menyediakan sarana dan prasarana kegiatan usaha soma pajeko. Biaya investasi terendah yaitu KM. Rico berjumlah Rp2.100.000,- dan tertinggi yaitu KM. Eunzo yaitu Rp 5.200.000.000,-.

\section{Biaya Tetap (Fixed Cost)}

Biaya tetap adalah pengeluaran bisnis yang tidak bergantung pada tingkat

Tabel 2. Biaya Tetap Nelayan Soma Pajeko di Pelabuhan Perikanan Pantai Tumumpa Kelurahan Tumumpa Dua

\begin{tabular}{|c|c|c|c|c|c|}
\hline \multirow[t]{2}{*}{ Biaya Tetap } & $\begin{array}{c}\text { Soma (umur } \\
\text { ekonomi } 3 \text { thn) }\end{array}$ & $\begin{array}{l}\text { Kapal (umur } \\
\text { ekonomi } 10 \text { th) }\end{array}$ & $\begin{array}{c}\text { Mesin (umur } \\
\text { ekonomi } 10 \mathrm{thn} \text { ) }\end{array}$ & Perawatan & \multirow[t]{2}{*}{ Jumlah } \\
\hline & \multicolumn{4}{|c|}{ Penyusutan (Rp) } & \\
\hline KM Rico & 50.000 .000 & 190.000 .000 & 5.000 .000 & 10.000 .000 & 255.000 .000 \\
\hline KM Laut Teberau & 66.666 .667 & 341.000 .000 & 40.000 .000 & 9.000 .000 & 456.666 .667 \\
\hline KM Makarios & 66.666 .667 & 194.000 .000 & 60.000 .000 & 6.000 .000 & 326.666 .667 \\
\hline KM Eunzo & 83.333 .333 & 195.000 .000 & 300.000 .000 & 5.000 .000 & 583.333 .333 \\
\hline KM Getsemani & 66.666 .667 & 245.000 .000 & 40.000 .000 & 5.000 .000 & 356.666 .667 \\
\hline KM Genesaret & 86.666 .667 & 396.000 .000 & 50.000 .000 & 4.000 .000 & 536.666 .667 \\
\hline Jumlah & 420.000.000 & 1.561.000.000 & 495.000.000 & 39.000.000 & 2.515 .000 .000 \\
\hline Rata-rata & 70.000.000 & 260.166 .667 & 82.500.000 & 6.500 .000 & 412.666 .667 \\
\hline
\end{tabular}

barang atau jasa yang dihasilkan oleh bisnis tersebut. Pengeluaran ini berkaitan dengan waktu, seperti gaji atau beban sewa yang dibayar setiap bulan, dan sering disebut sebagai pengeluaran tambahan. Ini berbeda dengan biaya variabel yang berkaitan dengan volume (dan dibayar per barang/jasa yang diproduksi). Biaya tetap juga didefenisikan sebagai pengaluran yang tidak berubah sebagai fungsi dari aktivitas suatu bisnis dalam periode yang sama.

Sumber: Hasil Olahan Data, 2019 


\section{Biaya Tidak Tetap (Variable Cost)}

Biaya variabel atau yang disebut juga dengan variable cost merupakan biaya yang dikeluarkan oleh sebuah perusahaan secara berubah-ubah yang didasarkan pada perubahan jumlah produk yang diproduksi. Semakin besar jumlah volume produk yang

Tabel 3. Biaya Variabel dan Pengeluaran Trip dari Masing-masing Kapal.

\begin{tabular}{|c|l|c|c|c|c|c|}
\hline No & \multicolumn{1}{|c|}{ Nama Kapal } & Ukuran (GT) & Solar (Liter) & Es (Balok) & Oli (Liter) & Garam (Kg) \\
\hline $\mathbf{1}$ & KM Laut Teberau & 54 & 2000 & 400 & 25 & 50 \\
\hline $\mathbf{2}$ & KM Rico & 54 & 3000 & 300 & 25 & 50 \\
\hline $\mathbf{3}$ & KM Makarios & 50 & 2000 & 400 & 80 & 200 \\
\hline $\mathbf{4}$ & KM Eunzo & 54 & 3000 & 300 & 25 & 100 \\
\hline $\mathbf{5}$ & KM Getsemani & 51 & 2000 & 200 & 30 & 50 \\
\hline $\mathbf{6}$ & KM Genesaret & 55 & 2500 & 250 & 25 & 150 \\
\hline
\end{tabular}

Sumber: Hasil Olahan Data, 2019

Tabel 4. Rekapitulasi Biaya Variabel

\begin{tabular}{|l|r|}
\hline & Variabel Cost \\
\hline KM Rico & 2.003 .000 .000 \\
\hline KM Laut Teberau & 2.558 .000 .000 \\
\hline KM Makarios & 1.974 .000 .000 \\
\hline KM Eunzo & 2.112 .000 .000 \\
\hline KM Getsemani & 1.209 .000 .000 \\
\hline KM Genesaret & 1.972 .500 .000 \\
\hline Jumlah & 11.828 .500 .000 \\
\hline Rata-rata & 1.971 .416 .667 \\
\hline
\end{tabular}

Sumber: Hasil Olahan Data, 2019

\section{Biaya total (Total Cost)}

Biaya total atau Total Cost (TC) adalah jumlah keselurûhan biaya tetap dan biaya variabel yang dikeluarkan oleh perusahaan untuk menghasilkan sejumlah produk dalam suatu periode tertentu, berdasarkan pengertian tersebut biaya total dapat dirumuskan sebagai berikut:

Tabel 5. Penerimaan Total dari Masing-masing Kapal

\begin{tabular}{|c|l|l|l|l|}
\hline No & \multicolumn{1}{|c|}{ Nama Kapal } & \multicolumn{1}{|c|}{$\begin{array}{c}\text { Kg/trip/bulan/tahun } \\
(\mathrm{Rp})\end{array}$} & $\begin{array}{c}\text { Rupiah/ trip } \\
(\mathrm{Rp})\end{array}$ & \multicolumn{1}{c|}{$\begin{array}{c}\text { Jumlah Penjualan } \\
(\mathrm{Rp})\end{array}$} \\
\hline 1 & KM. Rico & 10 ton $\times 2 \times 10=200.000$ & 11.000 & 2.200 .000 .000 \\
\hline 2 & KM Laut Teberau & 10 ton $\times 4 \times 10=400.000$ & 11.000 & 4.400 .000 .000 \\
\hline 3 & KM Makarios & 10 ton $\times 3 \times 10=300.000$ & 11.000 & 3.300 .000 .000 \\
\hline 4 & KM Eunzo & 10 ton $\times 3 \times 10=300.000$ & 11.000 & 3.300 .000 .000 \\
\hline 5 & KM Getsemani & 10 ton $\times 2 \times 10=200.000$ & 11.000 & 2.200 .000 .000 \\
\hline 6 & KM Genesaret & 10 ton $\times 3 \times 10=300.000$ & 11,000 & 3.300 .000 .000 \\
\hline
\end{tabular}

Hasil Dan Olahan Data, 2019 diproduksi oleh sebuah perusahaan maka semakin besar pula biaya yang harus dikeluarkan untuk memproduksi produk tersebut. Begitu pula sebaliknya, jika jumlah volume produk yang diproduksi kecil maka biaya yang dikeluarkan juga kecil.
$\mathrm{TC}=$ Biaya total $($ Total Cost $)$

$\mathrm{FC}=$ Biaya tetap (Fixed Cost)

$\mathrm{VC}=$ Biaya Variabel (Variable cost)

\section{Penerimaan Total (Total Revenue)}

Penerimaan total adalah jumlah seluruh penerimaan perusahaan dari hasil penjualan sejumlah produk (barang yang dihasilkan). Cara untuk menghitung penerimaan total dapat dilakukan dengan mengalikan jumlah produk dengan harga jual produk per unit. Jika dirumuskan sebagai berikut:

$$
\mathrm{TR}=\mathrm{Q} \times \mathrm{P}
$$

Dimana:

$$
\begin{array}{ll}
\text { TR } & =\text { Penerimaan total perusahaan } \\
Q & =\text { Jumlah produk yang dihasilkan } \\
P & =\text { Harga jual per unit }
\end{array}
$$
.

$\mathrm{TC}=\mathrm{FC}+\mathrm{VC}$ 


\section{Net B/C Ratio}

Rumus yang digunakan untuk menghitung Net $B / C$ adalah:

$$
N E T B / C=\frac{\sum_{t=1}^{n} \frac{B_{t}-C_{t}}{(1+i)^{t}}}{\sum_{t=1}^{n} \frac{C_{t}-B_{t}}{(1+i)^{t}}}
$$

Dimana :

$$
\begin{array}{ll}
\mathrm{B}_{\mathrm{t}} & =\text { Manfaat (Benefit) pada tahun ke-t } \\
\mathrm{C}_{\mathrm{t}} & =\text { Biaya (Cost) pada tahun ke-t } \\
\mathrm{i} & =\text { Discount Factor } \\
\mathrm{t} & =\text { Umur proyek }
\end{array}
$$

\section{$\mathrm{B} / \mathrm{C}$ Ratio $=2,67$}

Perhitungan B/C Ratio dari usaha kapal soma pajeko dapat dilanjutkan/ layak jika hasil analisis, yaitu:

\section{Jika $\quad$ B/C Ratio < 1 usulan investasi ditolak diterima \\ B/C Ratio > 1 usulan investasi dipertimbangkan}

Berdasarkan analisis kelayakan usaha kapal soma pajeko di Desa Tumumpa didapat nilai $B / C$ Ratio 2,67. Ratio ini menandakan bahwa usaha kapal soma pajeko di Desa Tumumpa Kecamatan Tuminting Kota Manado layak untuk dijalankan, karena manfaat dari kegiatan kapal soma pajeko lebih besar dari biaya.

\section{Net Present Value (NPV)}

Rumus umum yang digunakan dalam perhitungan NPV adalah:

$$
N P V=\sum_{t-1}^{T} \frac{C_{t}}{(1+r)^{t}}-C_{0}
$$

NPV $=$ Net Present Value (dalam Rupiah)

$\mathrm{Ct}=$ Arus Kas per Tahun pada Periode $\mathrm{t}$

$\mathrm{CO}=$ Nilai Investasi awal pada tahun ke 0 (dalam Rupiah)

$r \quad=$ Suku Bunga atau discount Rate (dalam \%)

$$
\mathrm{NPV}=2.065 .056 .607
$$

Penilaian terhadap kriteria NPV dilakukan dengan melihat hasil perhitungan NPV untuk setiap unit kapal soma pajeko dan suatu usaha dikatakan layak dari segi finansial apabila NPV barnilai positif. Berdasarkan analisis kelayakan usaha kapal soma pajeko di desa Tumumpa Kecamatan Tuminting Kota Manado didapat nilai NPV positif ini menandakan bahwa usaha kapal soma pajeko di Desa Tumumpa layak untuk dilaksanakan.

\section{Internal Rate of Return (IRR)}

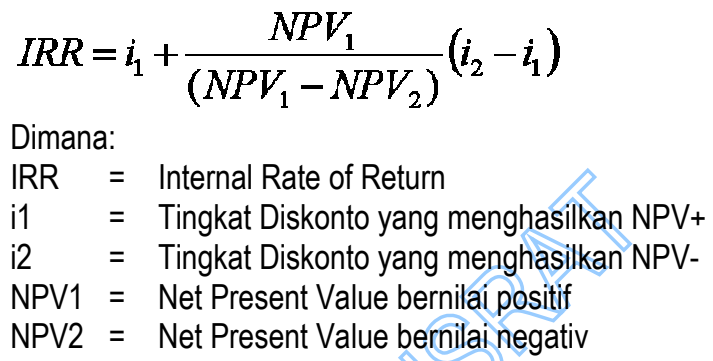

\section{$\mathrm{IRR}=46,3 \%$}

Penilaian terhadap kriteria IRR dilakukan dengan mengacu dari hasil perhitungan $\mathbb{R R}$ untuk setiap unit usaha kapal soma pajeko dan IRR suatu usaha layak, iika nilai IRR-nya lebih besar dari discount factor atau suku bunga kredit bank yang berlaku saat analisis.

Berdasarkan analisis kelayakan usaha didapat nilai IRR lebih besar dari discount factor atau suku bunga kredit bank sehingga usaha kapal soma pajeko di Desa Tumumpa Kecamatan Tuminting Kota Manado layak untuk dilaksanakan.

\section{Analisis Sensitivitas}

Kegunaa dari analisis sensitivitas, yaitu:

1. Menilai jumlah resiko yang ada

2. Menghitung dampak variasi pada manajemen usaha

3. Usaha manajemen yang lebih terarah.

Keuntungan :

1. Mengarahkan usaha manajemen

2. Sumber informasi perencana

3. Kemudahan otomatis

4. Membantu dalam pengambilan keputusan

5. Membantu menilai resiko suatu strategi

6. Membantu mengambil keputusan Yang tepat dan cepat 
Tabel 6. Analisis Sensivitas pada Penerapan Tingkat Persentase Penurunan 10\%, 15\% dan 21,64\% Harga Jual

\begin{tabular}{|l|l|l|l|}
\hline Sensivitas & NPV & IRR & B/C Ratio \\
\hline Penurunan 10\% & & & \\
\hline - Harga Jual & Rp. 542.321 .500 & $22,0 \%$ & 1,44 \\
\hline Penurunan 15\% & & & \\
\hline - Harga Jual & Rp. -219.046.053 & $7,5 \%$ & 0,82 \\
\hline Penurunan 21,64\% & & & \\
\hline - Harga Jual & Rp. -1.229.588.441 & \#NUM! & 0,00 \\
\hline
\end{tabular}

Sumber: Hasil Dan Olahan Data, 2019

Analisis sensitivitas usaha kapal soma pajeko terhadap penurunan harga jual $10 \%$ tidak mempengaruhi nilai NPV, IRR, B/C Ratio yang layak. Penurunan harga jual sebesar 21,64\% dapat mempengaruhi kelangsungan usaha kapal soma pajeko. Harga jual yang layak tidak bisa kurang dari harga Rp. 11.000 (Lampiran 4).

Dilihat dari Tabel 6 di atas di mana ketika harga jual turun $10 \%$ dan $15 \%$ dapat diketahui bahwa usaha kapal soma pajeko di

Tabel 7. Analisis Sensivitas pada Penerapan Tingkat Persentase Kenaikan 5\%, 10\% dan 23,43\% Variabel Cost

\begin{tabular}{|l|l|l|l|}
\hline Sensivitas & NPV & IRR & B/C Ratio \\
\hline Kenaikan 5\% & & & \\
\hline - Variabel Cost & Rp. 2.050.246.206 & $0,27 \%$ & 1,66 \\
\hline Kenaikan 10\% & & & \\
\hline - Variabel Cost & Rp. 1.492.569.193 & $0,17 \%$ & 1,21 \\
\hline Kenaikan 23,43\% & \multicolumn{1}{|c|}{. } & & \\
\hline - Variabel Cost & Rp. -3.609.864 & \#NUM! & 0,00 \\
\hline
\end{tabular}

Hasil Dan Olahan Data, 2019

Analisis sensitivitas usaha kapal soma pajeko terhadap kenaikan biaya variable cost jual $5 \%, 10 \%, 23,43 \%$ tidak mempengaruhi nilai NPV, IRR, B/C Ratio yang layak. Penurunan harga jual sebesar $50,74 \%$ dapat mempengaruhi kelangsungan usaha kapal soma pajeko.

Dilihat dari Tabel 7 di atas kita dapat membaca bahwa ketika kenaikan biaya variabel naik $5 \%$ maka akan diperoleh nilai NPV $=2,050,246,206.11$, IRR $=0.27 \%$, dan

Tabel 8. Analisis Sensivitas pada Penerapan Tingkat Persentase Penurunan 10\%, 15\% dan 21,63\% Produksi

\begin{tabular}{|l|l|l|l|}
\hline Sensivitas & NPV & IRR & B/C Ratio \\
\hline Penurunan 10\% & & & \\
\hline - Produksi & Rp. 542.321.500 & $22,0 \%$ & 1,44 \\
\hline Penurunan 15\% & & & \\
\hline - Produksi & Rp. -219.046.053 & $7,5 \%$ & 0,82 \\
\hline Penurunan 21,63\% & & & \\
\hline - Produksi & Rp. -1.229.023.419 & \#NUM! & 0,00 \\
\hline
\end{tabular}

Hasil Dan Olahan Data, 2019 
Dilihat dari Tabel 8 bahwa ketika penurunan produksi sebesar $10 \%$ maka usaha kapal soma pajeko di Desa Tumumpa, Kecamatan Tuminting, Kota Manado masih layak untuk dijalankan dikarenakan nilai NPV dari penurunan produksi $10 \%$ masih bernilai positif, nilai $\mathrm{B} / \mathrm{C}$ Ratio lebih dari 0 , dibandingkan dengan penurunan produksi sebesar $21,63 \%$ di mana kita ketahui bahwa usaha kapal soma pajeko sudah tidak layak untuk dijalankan dikarenakan NPV bernilai negative, suku bunga usaha lebih kecil dari suku bunga bank, dan B/C Ratio bernilai 0 .

Analisis sensitivitas bertujuan untuk melihat hasil kegiatan ekonomi bila ada kesalahan atau perubahan dalam perhitungan biaya atau benefit (Kadriah, 1988). Pada analisis ini jika disebut peka bila dengan adanya sedikit penurunan harga atau produksi menyebabkan usaha kapal soma pajeko sudah merugi. Sebaliknya, disebut tidak peka apabila sedikit penurunan harga dan produksi tidak menyebabkan usaha kapal soma pajeko berada pada kondisi rugi (Andyana et al., 1994).

Hasil penelitian yang dilakukan di Desa Tumumpa, komponen sensitivitas yang dianalisis yaitu: penurunan harga, penurunan produksi, kenaikan biaya tetap (fixed cost) dan kenaikan biaya variable (variable cost).

Berdasarkan hasil pengamatan pada usaha soma pajeko di Desa Tumumpa khususnya sensitivitas penurunan $10 \%$ dan $15 \%$ usaha tersebut belum mempengaruhi nilai NPV, IRR dan B/C Ratio yang layak. Penurunan produksi sebesar 21,63\% mengakibatkan perubahan pada nilai NPV, IRR, B/C ratio menjadi tidak layak dijalankan.
Tabel 9. Kriteria Kelayakan Finansial Usaha Soma Pajeko di Kelurahan Tumumpa

\begin{tabular}{|l|l|l|}
\hline No & Kriteria Kelayakan & Nilai \\
\hline 1 & NPV & Rp. 2.065 .056 .606 \\
\hline 2 & IRR (\%) & $46,26 \%$ \\
\hline 3 & B/C R & 2,67 \\
\hline \multicolumn{2}{|l|}{}
\end{tabular}

Setelah melakukan analisis dapat diketahui seberapa jauh dampak perubahan tersebut terhadap kelayakan suatu usaha. Tujuan yang pokok yaitu:

1. Memperbaharui cara pelaksanaan suatu usaha,

2. Memperbaharui design usaha perikanan sehingga usaha NPV.

3. Mengurangi resiko kerugian dengan menunjukan beberapa tindakan yang diambil.

Secara keseluruhan, dapatlah dikatakan bahwa usaha soma pajeko ini layak dilanjutkan melihat bahwa nilai NPV masih bernilai positif yaitu Rp2.065.056.606, nilai IRR lebih besar dari suku bunga bank yaitu $46,26 \%$, dan nilai $\mathrm{B} / \mathrm{C}$ Ratio lebih besar dari 0 yaitu 2,67 .

\section{KESIMPULAN}

Secara keseluruhan, dapatlah dikatakan bahwa usaha soma pajeko ini layak dilanjutkan melihat bahwa nilai NPV masih bernilai positif, nilai IRR lebih besar dari suku bunga bank dan nilai B/C Ratio lebih besar dari 1.

Kendala dalam usaha ini hanyalah berupa kenaikan harga BBM dan solusinya yang saya dapat kemukakan adalah dengan mengurangi trip agar biaya operasional dapat terjangkau.

\section{DAFTAR PUSTAKA}

Aan, K dan Djam'an, S. 2010. Metodologi Penelitian Kualitatif. Bandung: Alfabeta.

Arikunto, S. 2006. Metode Penelitian Kualitatif. Jakarta: Bumi Aksara.

Derman. 2015. Ekonomi Pesisir dan Dinamika Pendapatan Nelayan. 
Fathoni, A. 2006. Metodologi Penyusun Skripsi. Rineka Cipta: Jakarta. Halaman 103.

Gaspersz, Vincent. 2002. Pedoman Implementasi Program Six Sigma. Jakarta: Gramedia Pustaka Utama.

Gittinger, J. P. 1986. Analisa Ekonomi Proyek-Proyek Pertanian. Universitas Indonesian (UI-Press).

Hermawan, O.D. 2016. Hubungan Waktu Lama Pelingkaran Jaring dan Penarikan Tali Kerut Terhadap Total Hasil Tangkapan Alat Tangkap Purse Seine di Muncar, Kabupaten Banyuwangi, Jawa Timur. Hal 01-09 vol V No. 02.

Hidayat. 2004. Kajian Penangkapan Purse Seine dan Kemungkinan Pengembangannya di Indramayu. Bogor: IPB.

Japsamsah, C.I. 2015. Analisis Sensitivitas Usaha Budidaya Ikan Nila (Oreochromis niloticus) di Desa Tatelu Kecamatan Dimembe Kabupaten Minahasa Utara. Hal 87-90 vol III No. 5 (April 2015). ISSN.

Katiandagho, E. Paransa, I J. dan Kefi O. S. 2013. Sukses Pengoperasian Pukat Cincin Sinar Lestari 04 dengan Alat Bantu Rumpon Yang Beroperasi di Perairan Lolak Provinsi Sulawesi Utara. Hal 67-75 vol 1 No. 3 (Juni 2013. ISSN.

Kenanga, DT. 2012. Faktor-Faktor yang Mempengaruhi Pendapatan Usaha Perikanan Tangkap dengan Kapal Motor (Studi Kasus di Kota Bitung, Sulawesi Utara).

Kurniati, H. dan E. Susilawati. 2018. Analisis Kelayakan dan Sensitivitas: Studi Kasus Industi Kecil Tempe Kopti Semanan, Kecamatan Kalideres. Jakarta Barat. Hal 102-116 Vol 10 No. 2 (April 2018). ISSN.
Manoppo V. 2013. Mobilitas dan Alih Status Nelayan Skala Kecil di Provinsi Sulawesi Utara. Disertasi Pascasarjana IPB. Bogor.

Salatan, S. 2018. Strategi Pemberdayaan Masyarakat Nelayan Soma Pajeko di Kecamatan Salibabu Kabupaten Kepulauan Talaud Provinsi Sulawesi Utara. Hal 88 vol XIII No. 01 (Juni 2018).

Sismadi. 2006. Analisis Efisiensi Penggunaan Input Alat Tangkap Purse Seine di Kota Pekalongan.

Sondakh, V. 2017. Dinamika Kelompok Nelayan Tradisional Kelurahan Malalayang Satu Timur Kecamatan Malalayang Kota Manado. Hal 03 Vol 5 No. 09 (April 2017) ISSN.

Suaedi. 2013. Metode Kuantitatif Untuk Analisis Kebijakan. Palopo: IPB Press.

Sufirudin. 2016. Hubungan Patron Klien Diantara Masyarakat Nelayan di Desa Kangkunawe Kecamatan Maginti Kabupaten Muna Barat Provinsi Sulawesi Tenggara.

Sugiyono. 2008. Metode Penelitian Kuantitatif Kualitatif dan R\&D. Bandung. Alfabeta. Halaman 80.

Wiyono, E. S. John H \& B.H. Iskandar. 2012. Sensitivitas Usaha Perikanan Gillnet di Kota Tegal, Provinsi Jawa Tengah. Buletin PSP, Volume 20 No.2 Edisi April 2012. ISSN 0251$281 \times$ halaman $131-14$

Wulandari, P. 2012. Analisis Kelayakan Finansial Pengembangan Usaha Kecil Menengah (UKM) Nata De Coco di Sumedang, Jawa Barat. Hal 113-120 vol 1 No. 2 (Mei 2012). 


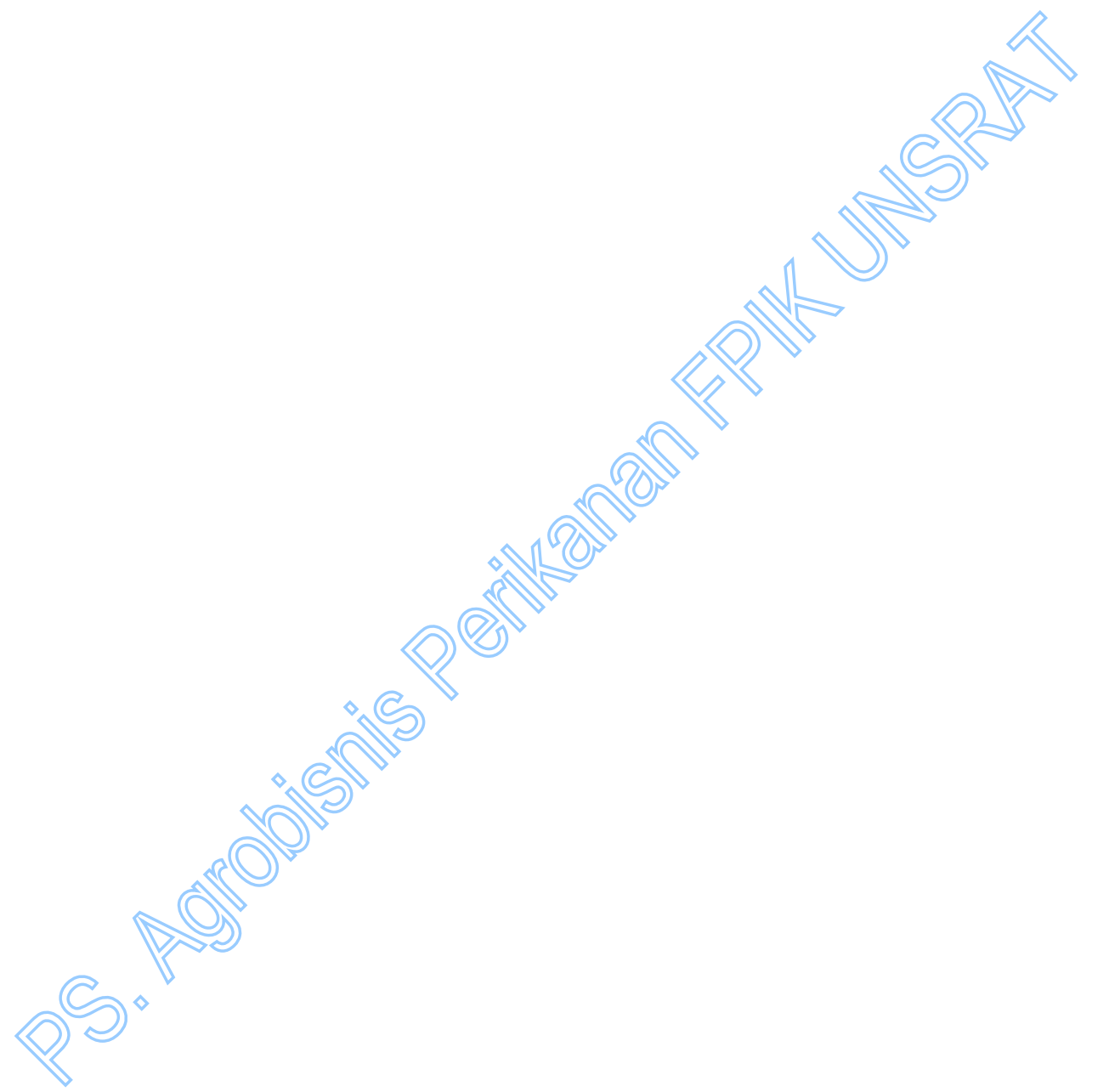

